\title{
Gender Difference in Cocaine-Induced HPA Axis Activation
}

\author{
Cynthia Kuhn, Ph.D. and Reynold Francis, M.S.
}

The study investigates the influence of gender on the activation of the hypothalamo-pituitary-adrenal (HPA) axis by cocaine and other monamine uptake inhibitors. Drug-induced secretion of adrenocorticotrophic hormone (ACTH) was used to pursue this question. Cocaine produced a dose-related rise in serum ACTH levels in both male and female rats, but the rise was significantly greater in females than in males. Females also showed enhanced HPA axis activation following administration of the dopamine uptake inhibitor GBR 12909, the serotonin uptake inhibitor fluoxetine, and the norepinephrine uptake inhibitor desipramine. No gender difference in HPA axis activation was observed in a doseresponse study of cocaine-induced HPA activation in 10

KEY WORDs: Cocaine; Gender; Females; HPA axis; ACTH

The locomotor stimulant cocaine produces a marked, but brief, activation of the hypothalamo-pituitary-adrenal (HPA) axis (Kuhn and Little 1995). This activation is mediated by enhanced release of corticotropin-releasing factor (CRF) from hypothalamic neurons, as pretreatment of animals with either a CRF antagonist or antibody to CRF can eliminate cocaine-induced adrenocorticotrophic hormone (ACTH) secretion (Rivier and Vale 1987; Sarnyai et al. 1992). HPA axis activation by cocaine may be more than an epiphenomenon unrelated to the better-characterized behavioral activation; it may play a mediating role in these behaviors either through central actions of CRF to stimulate CRF recep-

From the Department of Pharmacology, Duke University Medical Center, Durham, North Carolina.

Address correspondence to: Dr. Cynthia Kuhn, Department of Pharmacology, Duke University Medical Center, Durham, North Carolina 27710.

Received September 5, 1996; revised, accepted November 8, 1996. day old rats. Ovariectomy of females decreased the ACTH response to cocaine, but castration did not affect the response of males. To evaluate the role of the pituitary in this gender difference, ACTH levels were determined after corticotropin-releasing factor (CRF) administration. Females showed greater ACTH responses to CRF than males. These studies demonstrate that female rats show exaggerated HPA responses to monoamine uptake inhibitors and that enhanced pituitary responsivity to $C R F$ contributes to this gender difference.

[Neuropsychopharmacology 16:399-407, 1997] (C) 1997 American College of Neuropsychopharmacology

tors that release dopamine (Kalivas et al. 1987; Lavicky and Dunn 1993) or through glucocorticoid hormones themselves. Manipulation of glucocorticoid levels influences locomotor responses to cocaine (Marineli et al. 1994; Piazza et al. 1994), as well as the development of sensitized responses following food restriction, stress or cocaine administration (Derouche et al. 1992, 1993; Rouge-Pont et al. 1995).

Cocaine produces most of its effects, including neuroendocrine effects by inhibiting the reuptake of the monoaminergic neurotransmitters norepinephrine, dopamine, and serotonin (Levy et al. 1994). All three of these monaminergic transmitters exert stimulatory control over CRF release in rats, as shown by stimulation following the administration of receptor agonists or uptake inhibitors (Plotsky et al. 1989; Fuller 1990; Borowsky and Kuhn 1991, 1993). The actions of cocaine probably reflect the summation of these actions. Serotonin, dopamine, and norepinephrine antagonists or neurotoxic damage to norepinephrine and dopamine neurons all diminish cocaine-induced ACTH secretion (Borowsky 
and Kuhn 1991; Levy et al. 1991, Sarnyai et al. 1992). Through the CRF mechanisms described, activation of monoaminergic neurons in the hypothalamus may contribute to the behaviorally activating effects of locomotor stimulants.

Significant sexual dimorphism exists in HPA activation by experimental stressors in rats. Female rats show exaggerated diurnal peaks of corticosterone (Critchlow et al. 1963) and enhanced ACTH and corticosterone responses to stressors including ether and restraint (Le Mevel et al. 1978, 1979; Lesniewska et al. 1990; Ehlers et al. 1993; Aloisi et al. 1994). However, the exact site of this gender difference is a matter of some controversy. The presence or absence of gender effects on hypothalamic CRF production (Buckingham et al. 1982; Watts and Swanson 1989), pituitary sensitivity to CRF (Coyne and Kitay 1969; Buckingham et al. 1982), and adrenal sensitivity to ACTH (Spinedi et al. 1992) have been reported. These gender differences in HPA reactivity suggest that cocaine should elicit greater HPA activation in females than in males.

Such a gender difference in HPA activation could have important clinical significance. Female rats show exaggerated locomotor activation after initial administration of amphetamine (Van Haaren and Meyer 1991) or cocaine (Becker et al. 1982) and show greater sensitization during chronic administration of these locomotor stimulants (Camp and Robinson 1988a, 1988b; Van Haaren and Meyer 1991). These animal models are thought to be representative of the dopaminergic responses that mediate stimulant self-administration (Le Moal and Simon 1991). Recent reports that circulating corticosterone levels influence the establishment of stimulant self-administration (Piazza et al. 1991), as well as studies indicating a role for CRF in stimulant sensitization (Cole et al. 1990a, 1990b), support a role for the HPA axis in this process. The evidence reviewed suggesting that females might exhibit enhanced HPA responses to cocaine indicates a potential explanation for the reported gender differences in stimulant responsivity.

This study investigates the possibility that female rats show exaggerated HPA activation following administration of cocaine or other monoamine uptake inhibitors. To accomplish this goal, serum ACTH was used to determine HPA activation following administration of cocaine, GBR12909, desipramine, and fluoxetine.

\section{METHODS}

\section{Animals}

Male and female rats were obtained from Charles River Laboratories (Raleigh, NC). Adults were separated by gender and placed two per cage in plastic cages. Intact females were used without regard to state of the estrous cycle. Ovariectomized females and castrated males were prepared surgically by the supplier and delivered 1 week postsurgery. For developmental studies, lactating dams with litters were obtained from the same supplier and housed in large plastic maternity cages. All animals were obtained from the supplier at least 4 days before the experiment. Gonadectomized animals were used 2 weeks after surgery. All animals were housed in a vivarium with a 12-hour light-dark cycle and given food and water ad libitum. Rats were moved to the laboratory at least 2 days before the experiment to minimize stressinduced changes in hormone secretion on the day of the experiment. All animals were acclimated to the injection procedure with daily injections of saline for 3 days before the experiment. Males and females were always run at the same time, and all experiments were conducted between 8:00 am and 10:00 am to control for diurnal variations in $\mathrm{ACTH}$ secretion.

\section{Drug Treatments}

A similar experimental design was used in all studies: animals were brought to the laboratory 2 days before the experiment and treated either with vehicle or appropriate drug, killed at the appropriate time after drug administration and blood collected for determination of ACTH by radioimmunoassay, (RIA). All drugs used were dissolved in saline, except GBR12909 and fluoxetine, which were dissolved in distilled water. Cocaine hydrochloride, desipramine, fluoxetine, and GBR 12909 were administered IP, and CRF was administered SC. Controls for each experiment were treated with appropriate vehicle delivered by the same route. Controls for the dose-response experiments were injected and killed at the same time as drug-injected animals. Controls for the time course experiment were injected with saline, and killed at the same times as cocaine-treated animals. Trunk blood was collected after decapitation, centrifuged at 3,000 times for 15 minutes, and serum stored at $-80^{\circ} \mathrm{C}$ until assayed. All animal protocols were performed according to guidelines established by the Guide for the Care and Use of Laboratory Animals and approved under an existing Animal Welfare Assurance Protocol.

\section{ACTH Assay}

ACTH levels were determined by RIA. The ACTH assay utilized an antibody directed toward the 14-24 portion of the molecule that was provided by IgG Corporation (Nashville,TN). Cross-reactivity of this antibody is $100 \%$ with human ACTH (1-24) and porcine ACTH (1-39). ${ }^{125} \mathrm{I}$-ACTH was provided by INCSTAR (Stillwater, MN), and synthetic ACTH standards were provided by Peninsula Labs (Belmont, CA). Sensitivity of the ACTH assay is $3 \mathrm{pg} / \mathrm{ml}$, and inter- and intraassay coefficients of variation are $12 \%$ and $8 \%$, respectively. 


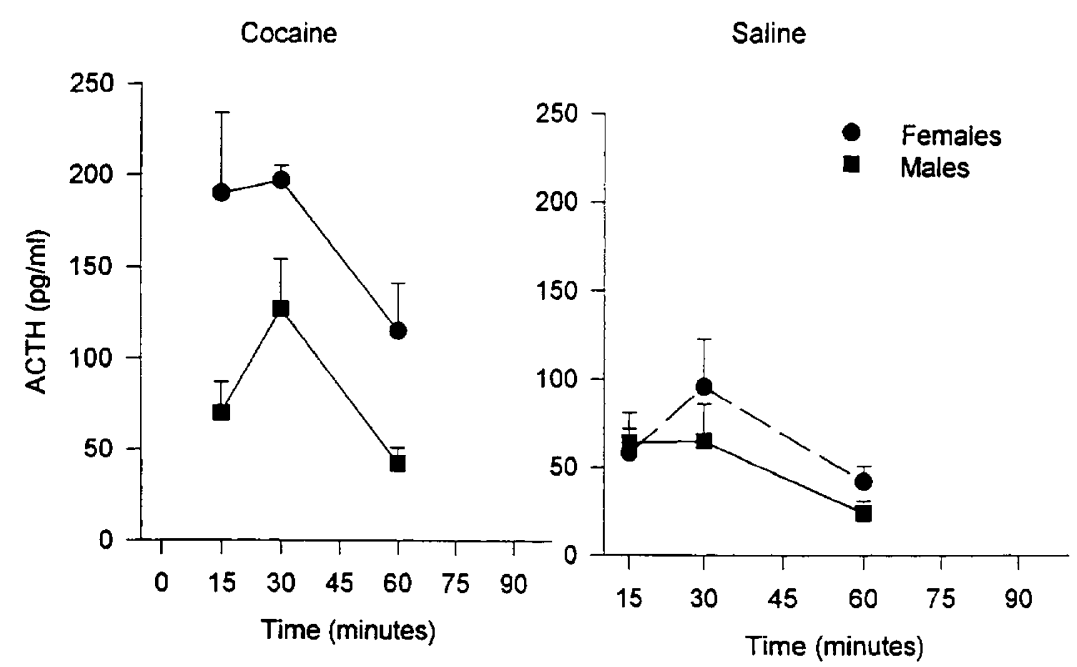

Figure 1. Time course of ACTH response to cocaine in males and females. Rats were injected with saline or cocaine $(20 \mathrm{mg} / \mathrm{kg}$ IP), killed at various times after injection and serum ACTH determined. Values from saline-injected animals were pooled and shown at $t=0$ for clarity of presentation. Solid circles, females; solid squares, males. Result are expressed as mean (pg/ $\mathrm{ml}) \pm$ SEM. $N=6-8$ /time point (21-23 for pooled saline controls). Gender-treatment interaction, $p<.02$.

\section{Drugs}

Cocaine hydrochloride was provided by Research Triangle Institute through an arrangement with the $\mathrm{Na}$ tional Institute for Drug Abuse (NIDA). Desipramine hydrochloride and GBR 12909 were provided by RBI Biochemicals (Natick, MA). Fluoxetine hydrochloride was a gift from Eli Lilly Company (Indianapolis, IN).

\section{Statistics}

All experimental subjects were compared to vehicleinjected, time-matched controls. Results are expressed as mean \pm SEM. Two-way analysis of variance (ANOVA) was used to determine the impact of gender on doseresponse relationships, and three-way ANOVA was used to determine gender effects on the time course of the response to cocaine and the effect of gonadectomy. For studies in which data exhibited a significant gender times treatment interaction, a lower-order ANOVA was conducted to establish main treatment effect by gender, and Fisher's least significant difference test was used to assess differences between groups when ANOVA revealed statistical differences in treatment groups. The level of significance was set at $p<.05$.

\section{RESULTS}

\section{Gender Differences in ACTH Response to Cocaine}

The time course for the effect of cocaine $(20 \mathrm{mg} / \mathrm{kg} \mathrm{IP}$ ) on ACTH secretion in males and females is shown in (Figure 1). The time-matched saline controls for each gender have been averaged and shown at $t=0$ for clarity of presentation, but all statistical analysis was conducted using time-matched controls. cocaine induced a significant ACTH response in both groups, but the females demonstrated a significantly greater response $F$ $(1,77)$ for an effect of cocaine treatment, $=17.7, p<.002$,
$F(1,77)=10.2, p<.004$, for an effect of gender; $F(1,77)=$ $5.6, p<.02$, for an interaction of gender by cocaine treatment. The dose-response curve for cocaine-induced $\mathrm{ACTH}$ secretion is shown in (Figure 2). In this experiment, animals were killed 30 minutes after cocaine or saline administration, when cocaine-induced stimulation is greatest. Cocaine produced a significant stimulation of $\mathrm{ACTH}$ secretion, but this effect was greater in females $[F(3,188)=16.3, p<.0001$, for an effect of dose; $F(1,188)=31.6, p<.0001$, for an effect of gender].

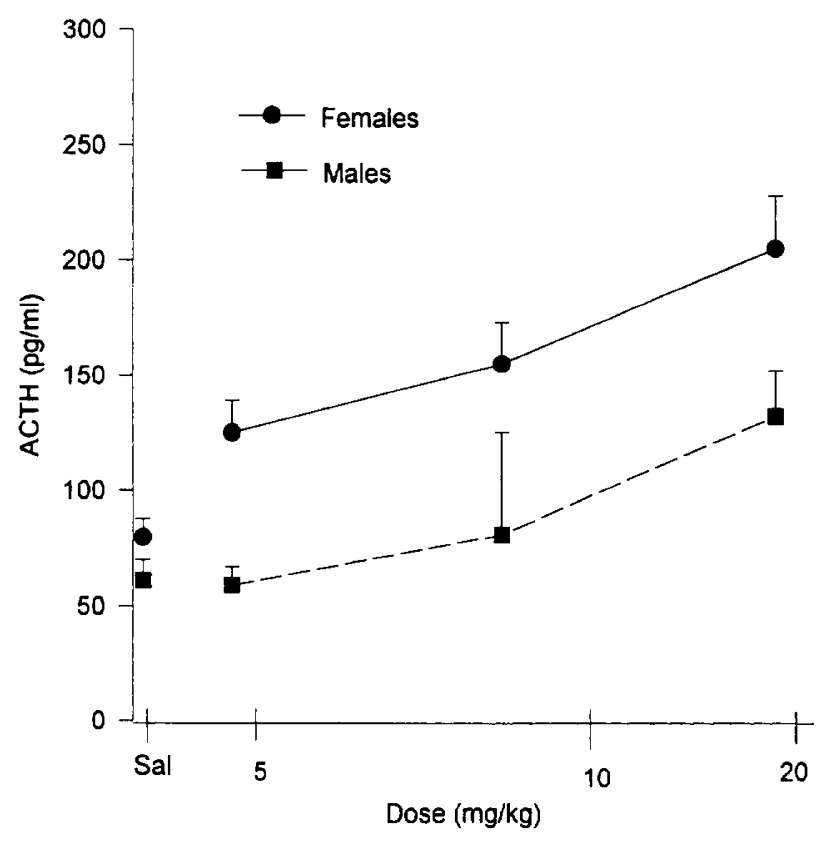

Figure 2. Dose-response curve for cocaine-induced ACTH secretion in males (solid squares) and females (solid circles). Rats were injected with saline or cocaine $(5,10$, or $20 \mathrm{mg} / \mathrm{kg}$ IP) and killed 30 minutes after injection. Results are expressed as mean $(\mathrm{pg} / \mathrm{ml}) \pm \mathrm{SEM} . N=23-26$ /group. Effect of gender, $p<.001$. 


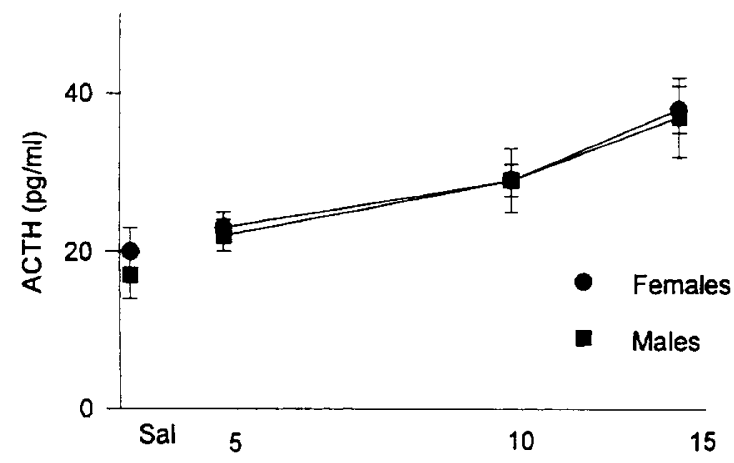

Figure 3. Dose-response curve for cocaine-induced ACTH secretion in neonatal (postnatal day 10) males (solid squares) and females (solid circles). Rats were injected with saline or cocaine $(5,10$, or $15 \mathrm{mg} / \mathrm{kg}$ IP) and killed 30 minutes after injection. Results are expressed as mean (pg/ml) \pm SEM. $N=$ 10-12/group.

Two preliminary approaches were used to address whether the gender difference reflected gonadal hormone status. First, the ACTH response to cocaine was studied in prepubertal animals (postnatal day 10). Second, the ACTH response to cocaine was determined in ovariectomized and castrated rats. The dose-response curve for cocaine-induced ACTH secretion in suckling rats (postnatal day 10) is shown in (Figure 3). In this experiment, the maximum dose used was decreased to 15 $\mathrm{mg} / \mathrm{kg}$ because $20 \mathrm{mg} / \mathrm{kg}$ caused seizures in the pups

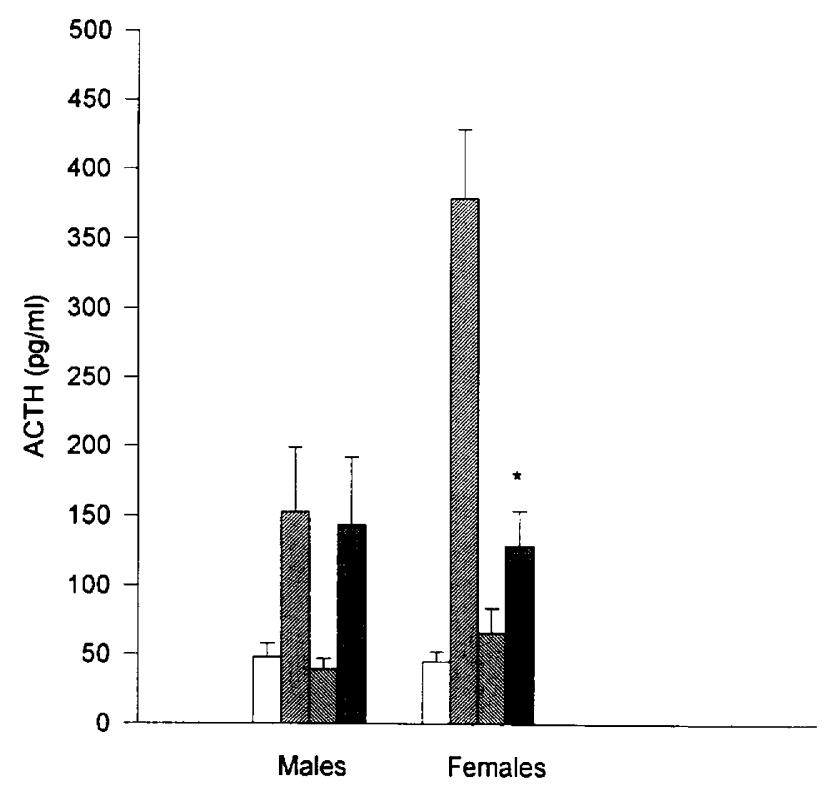

Figure 4. Effect of gonadectomy on ACTH response to cocaine in males and females. Sham-operated or gonadectomized males and females were treated with saline or cocaine $(15 \mathrm{mg} / \mathrm{kg})$, killed 30 minutes later and serum ACTH determined. Results are expressed as mean $(\mathrm{pg} / \mathrm{ml}) \pm$ SEM. $N=$ $6-8$ /group. ${ }^{*} p<.01$ relative to intact cocaine-treated female.

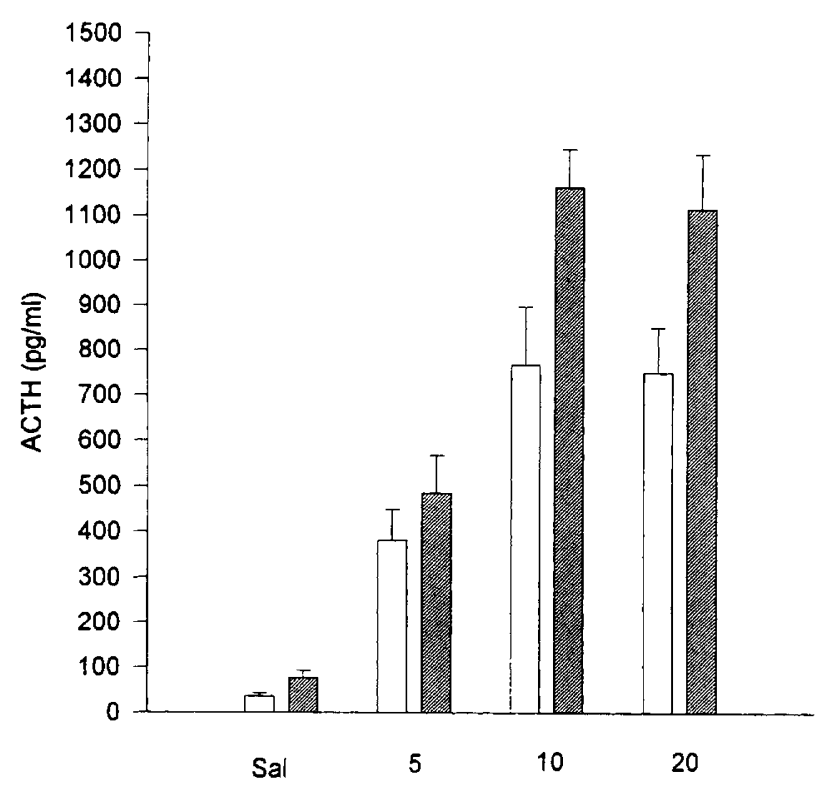

Figure 5. Effect of fluoxetine on ACTH secretion. Rats were injected with $\mathrm{d}_{2} 0$ or fluoxetine $(5,10$, or $20 \mathrm{mg} / \mathrm{kg} \mathrm{IP})$ and killed 30 minutes after injection. Open bars, males; crosshatched bars, females. Results are expressed as mean (pg/ml) \pm SEM. $N=8$ /group. Effect of gender, $p<.0001$.

(unpublished observations). Cocaine elicited a small, but statistically significant, rise in ACTH secretion [ $F$ $(3,79)=13.8, p<.0001$, for an effect of dose] that was similar in both males and females.

The effect of gonadectomy on the ACTH response to cocaine 30 minutes after administration is shown in (Figure 4). A submaximal dose ( $15 \mathrm{mg} / \mathrm{kg}$ ) was used in this study to permit detection of either increases or decreases in the response. Cocaine induced significant ACTH secretion under all conditions $[F(1,45=42.2, p<$ .0001 , for an effect of drug]. However, gonadectomy significantly influenced the response to cocaine $[F(2,45=$ $7.9, p<.001$, for an interaction of gonadectomy with gender]. The figure demonstrates that castration of males did not influence either basal ACTH secretion or cocaine-induced secretion, whereas ovariectomy significantly lowered the ACTH response to cocaine $[F(1,21)=$ 13.9, $p<.001$ for an effect of surgery; $F(1,21)=42.1, p<$ .0001 , for an effect of cocaine, $F(1,21)=19.5, p<.0002$, for an interaction of surgery and cocaine treatment].

To investigate the relative importance of gender on the secretion of ACTH associated with inhibition of serotonin, dopamine, or norepinephrine uptake, ACTH responses to more selective uptake inhibitors were evaluated in males and females. The effect of various doses of the serotonin uptake inhibitor fluoxetine, the norepinephrine uptake inhibitor desipramine, and the dopamine uptake inhibitor GBR12909 on ACTH levels in males and females are shown in (Figures 5 to 7). Doses 


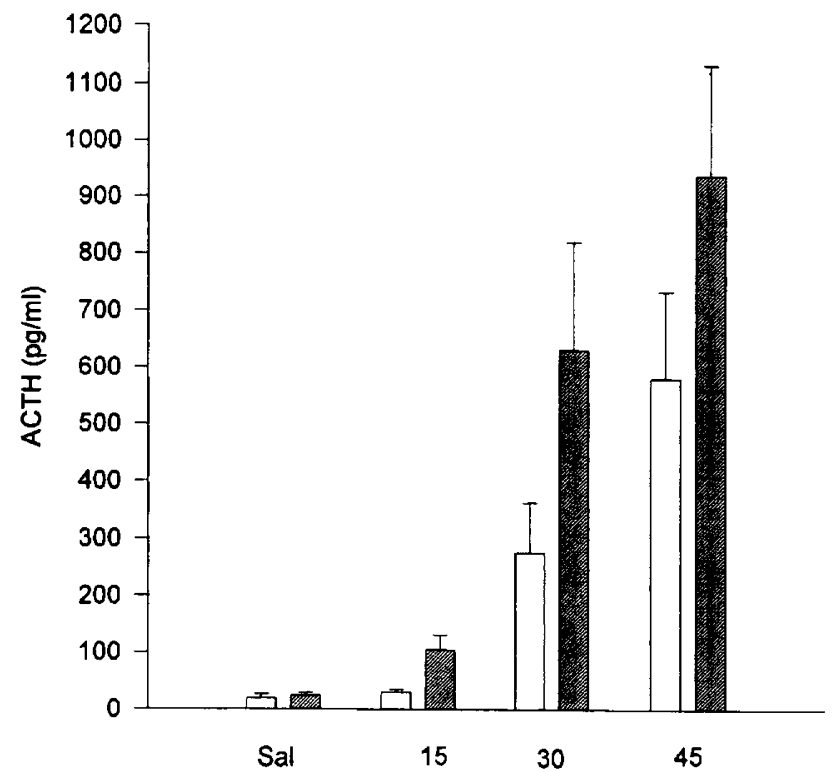

Figure 6. Effect of desipramine on ACTH secretion. Rats were injected with saline or desipramine $(15,30$, or $45 \mathrm{mg} / \mathrm{kg}$ IP), and killed 60 minutes after injection. Open bars, males; cross-hatched bars, females. Results are expressed as mean $(\mathrm{pg} / \mathrm{ml}) \pm$ SEM. $N=8$ /group. Effect of gender, $p<.01$.

and times used were those established in a previous study to elicit maximal ACTH secretion (Borowsky and Kuhn, 1991). All three drugs stimulated ACTH secretion more than cocaine in both males and females. Fe-

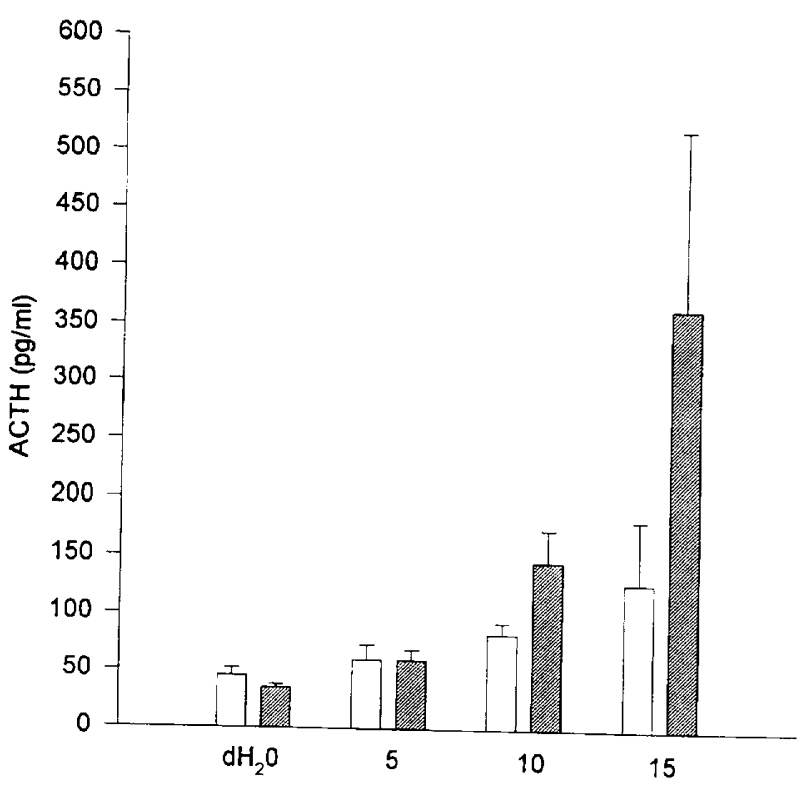

Figure 7. Effect of GBR 12909 on ACTH secretion. Rats were injected with $d_{2} 0$ or GBR $12909(5,10$, or $15 \mathrm{mg} / \mathrm{kg} \mathrm{IP)}$, and killed 30 minutes after injection. Open bars, males; crosshatched bars; females. Results are expressed as mean $(\mathrm{pg} / \mathrm{ml}) \pm$ SEM. $N=19-20$ for saline, $n=8$ for $5 \mathrm{mg} / \mathrm{kg}, n=15$ for 10 $\mathrm{mg} / \mathrm{kg}$, and $n=7-8$ for $15 \mathrm{mg} / \mathrm{kg}$. Effect of gender, $p<.01$.
Table 1. ACTH Response to CRF In Males and Females

\begin{tabular}{lcc}
\hline Treatment & Males & Females \\
\hline Saline & $23 \pm 2(8)$ & $37 \pm 8(8)$ \\
$0.1 \mu \mathrm{g} \mathrm{CRF}$ & $100 \pm 15(6)$ & $369 \pm 114^{*}(6)$ \\
$1.0 \mu \mathrm{g} \mathrm{CRF}$ & $369 \pm 114(6)$ & $628 \pm 99^{*}(6)$ \\
\hline
\end{tabular}

Animals were injected with saline or CRF (SC), killed 30 minutes later, and the serum ACTH determined as described in Methods. Results are expressed as mean $(\mathrm{pg} / \mathrm{ml}) \pm \mathrm{SEM} . N$ is indicated in parentheses. *Significantly different from males, $p<.001$.

males showed responses greater than males for fluoxetine $[F(3,48)=55.7, p<.0004$, for an effect of dose; $F(1,48=$ 14.7 for an effect of gender], desipramine $[F(3,52)=21.3$; $p<.0001$, for an effect of dose; $F(1,52)=6.9, p<.01$, for an effect of gender] and for GBR $12902[F(3,93)=8.6, p<$ .0001 , for an effect of dose; $F(1,93)=6.1, p<.015$, for an effect of gender; $F(3,93)=6.1, p<.0001$, for an effect of dose; $F(3,93)=3.1, p<.013$, for an interaction of dose and gender].

The significantly greater HPA response of females to cocaine and to the more specific uptake inhibitors suggested that hypothalamic CRF release or pituitary response to CRF represented a likely site of gender difference. To evaluate the latter possibility, ACTH response to exogenously administered CRF was determined in male and female rats. The results of this experiment are shown in Table 1. As with cocaine and more specific uptake inhibitors, females showed considerably greater ACTH responses to CRF than did males $[F(2,34)=23.1$, $p<.0001$, for an effect of CRF; $F(1,32=10.0, p<.0033$, for an effect of gender].

Gender differences in basal ACTH levels were observed in some experiments. ANOVA of basal hormone levels from all experiments revealed an effect of gender $[F(1,109)=4.8, p<.05]$ and an effect of experiment $[F(5,109)=5.4, p<.01]$.

\section{DISCUSSION}

The major finding of the present study is that female rats exhibit greater HPA activation following administration of cocaine or more selective monoamine uptake inhibitors. Females showed greater ACTH responses than males following administration of cocaine, the serotonin uptake inhibitor fluoxetine, the norepinephrine uptake inhibitor desipramine, or the dopamine uptake inhibitor GBR 12909. The enhanced response of females to exogenous CRF suggests that the pituitary corticotrophs might represent at least one site from which this gender difference originates.

The enhanced ACTH response to monoamine uptake inhibitors in females is consistent with a significant literature demonstrating greater HPA reactivity in female 
rats to other stimuli. Both ACTH and corticosterone show lager fluctuations in females during the normal diurnal rhythm (Critchlow et al. 1963) and in response to experimental stressors like restraint (Kitay 1963; Le Mevel et al. 1978, 1979; Aloisi et al. 1994; Chisari et al. 1995, as well as immune modulators (Rivier 1994) and alcohol (Rivier 1993). The finding that responses in the present study were enhanced following administration of a number of agents that act through different neurochemical mechanisms suggests that the critical site for gender difference exists downstream from neurotransmitter modulation of CRF release. Such differences could derive from enhanced production and release of $C R F$, enhanced responsivity of the pituitary to CRF, enhanced ACTH production by the pituitary, or enhanced adrenocortical responses to stimuli. In fact, gender effects at several of these sites have been described.

The present data support a role for the pituitary in the enhanced responses that were observed, as females showed higher ACTH secretion in response to CRF. This finding is consistent with reports of enhanced ACTH production following CRF challenge in pituitary gland of female compared to male rats (Coyne and $\mathrm{Ki}$ tay 1969, 1971), although contradictory findings have been reported (Miskowiak et al. 1988). As pituitary CRF receptor number is reported to be lower in females than in males (Ehlers et al. 1993), these findings suggest that the signal transduction cascade through which CRF stimulates ACTH synthesis and secretion may represent an important candidate for further investigation of gender differences.

Gender differences in hypothalamic mechanisms regulating CRF synthesis and release could also have contributed to the observed results. Pituitary glands from females are reported to release more CRF during in vitro incubations than those from males (Buckingham 1982), and females show enhanced excursions of prepro-CRF mRNA levels during the diurnal cycle relative to males (Watts and Swanson 1989). In addition, estrogen stimulates expression of the CRF gene in ovariectomized rats (Patchev et al. 1995). Finally, ovariectomy decreases and estradiol restores CRH synthesis (Haas and George 1988).

Inconsistent gender differences in basal ACTH secretion were noted in the present study. Females showed slightly enhanced levels in the dose-response and fluoxetine studies but not in the others. Unpredictable day-to-day variations in the contribution of stress to the basal ACTH observed following saline injection probably contributed to this variability. As noted, stressinduced ACTH secretion shows greater gender differences than does basal secretion (Critchlow et al. 1963; Aloisi et al. 1994). As males and females from the same drug treatment were always run on the same day, these differences should result (as they did) in experiment-toexperiment variability, but in internal consistency in evaluating the impact of gender on the response to a particular drug.

Adrenocortical secretion of corticosterone also represents a site of gender differences in HPA reactivity, although this is not a focus of the present investigation. The adrenal cortex may be a site at which testosterone actually suppresses HPA function, as gonadectomy has been reported to augment and testosterone suppress endotoxin-induced corticosterone secretion in both immature rats and mice (Shanks et al. 1994; Spinedi et al. 1992).

Two findings in the present study suggest that the gender difference in ACTH responses to cocaine reflects a facilitating effect of estradiol and/or progesterone on these responses. First, the responses were absent before puberty, when levels of gonadal steroids are fairly low. Second, and more important, ovariectomy suppressed the ACTH response to cocaine in females, whereas castration did not influence the response in males. Decreased HPA responses in ovariectomized females but not castrated males have been observed in other studies as early as day 3 of postnatal life (Shanks et al. 1994) as well as in adulthood (Burgess and Handa 1992). Pharmacological replacement studies, as well as endocrine ablation studies, further support a role for estradiol and/or progesterone in enhanced HPA reactivity to stimuli. Sequential endocrine replacement mimicking the changes that occur during the estrous cycle demonstrated that a transient rise in estradiol augments the ACTH response to a stressor (Viau and Meaney 1991). Estrogen treatment of ovariectomized females increases CRF production in the hypothalamus, $\mathrm{ACTH}$, and corticosterone production to stressors (Kitay 1963; Lesniewska et al. 1990) and pituitary responsivity to CRF (Coyne and Kitay 1969). Although suppressive actions of estradiol on pituitary proopiomelanocortin and on HPA reactivity to stress have been reported (Redei et al. 1994), the replacement regimens involved in the latter study were supraphysiological, leading the authors to speculate that normal and supraphysiological levels of estrogen could produce different effects on HPA reactivity.

The females in the present study were used without regard to estrous cycle. This strategy was based on the assumption that variations in gonadal steroid hormone levels in the physiological range through the cycle would produce changes smaller than those that exist between males and females. The present study did demonstrate robust gender differences, as did previous studies that used females without regard to estrous state (Le Mevel et al. 1979; Lesniewska et al. 1990; Aloisi et al. 1994; Chisari et al. 1995). However, it is possible that these gender differences could be most evident during a specific phase of the cycle and that reactivity in females during a particular phase might not differ from males. The study of Viau and Meaney (1991) clearly demonstrated that HPA reactivity is enhanced 
during proestrous and altered by pharmacologically induced changes in gonadal steroid availability resembling those that occur during the female estrous cycle. Differences across the estrous cycle in the HPA response to alcohol also have been reported (Rivier 1993), but this study did not directly compare the responses of males to those of female at various stages in the cycle. Clearly, further studies in this area are needed.

The lack of significant gender differences in HPA reactivity of prepubertal rats adds to an already conflicting literature about the existence and endocrine mediators of gender differences in HPA reactivity in prepubertal rats. Although such differences have been reported (Tang and Phillips 1977; Hary et al. 1981, 1986), most studies, including the present one, fail to detect these differences (Rivier 1994; Walker et al. 1991; Schoenfeld et al. 1980). This disparity may be less important than it seems, as generally the gender differences observed during the first 2 weeks of postnatal life are smaller although detectable, than those that exist after puberty.

Gender differences exist in acute behavioral responses to cocaine and amphetamine (Savageau and Beatty 1981; Van Haaren and Meyer 1991) and in the sensitized responses observed after chronic treatment (Camp and Robinson 1988a). Estradiol potentiation of both dopamine release and dopamine receptor sensitivity supported a role for these elements of dopaminergic transmission as likely contributors for the gender differences in acute response (Hruska 1986; Becker and Cha 1989; Becker 1990; Morissette and Di Paolo 1993). However, an additional role for the HPA axis in this gender difference is supported by findings that corticosterone facilitates locomotor responses to cocaine (Marineli et al. 1994), whereas inhibition of glucocorticoid synthesis impairs it (Piazza et al. 1994).

The role of gonadal and adrenal steroids in sensitized responding may be somewhat different from the acute response. Reports that the HPA response contributes to the sensitized responses to locomotor stimulants associated with previous stress experience (Derouche et al. 1992), food restriction (Derouche et al. 1993), and previous cocaine treatment (RougePont et al. 1995) contribute, along with the present study, to the possibility that gender differences in sensitization could reflect gender differences in HPA activation. However, gonadectomy did not influence the sensitization of females to amphetamine, although it enhanced responses of males (Camp and Robinson 1988b). This raises an apparent inconsistency with the present study. However, contradictory findings about the role of glucocorticoids have been reported (Badiani et al. 1995; Cador et al. 1993), and clearly, factors than HPA axis activation are involved in stimulant sensitization.

Gender differences in drug metabolism do no seem to represent a critical determinant of the response to locomotor stimulants, although cocaine and amphet- amine differ significantly in this regard. Significant gender differences in amphetamine metabolism might have contributed to the findings of Camp and Robinson (Meyer and Lytle, 1978), although the authors did compensate for this by administering different doses of amphetamine to males and females. Preliminary findings from this laboratory indicate that there are no significant gender differences in brain cocaine levels in rats (Bowman et al. 1996).

The enhanced HPA reactivity to cocaine and pituitary sensitivity to CRF raise the intriguing possibility that this characteristic represents a "biological vulnerability" of females to cocaine abuse. However, this speculation contrasts with the known epidemiology of cocaine abuse, as male cocaine users outnumber female cocaine users by a 2-to-1 margin (National Institute for Drug Abuse 1990). Furthermore, recent studies by Lukas (1996) suggest that subjective effects of cocaine in human subjects may not show striking gender differences. Clearly, investigating gender differences in central actions of CRF represents an important future direction.

\section{ACKNOWLEDGMENTS}

This study was supported by NIDA grant \#09079.

\section{REFERENCES}

Aloisi AM, Steenbergen HL, Van de Poll NE, Farabollini F (1994): Sex-dependent effects of restraint on nociception and pituitary adrenal hormones in the rat. Physiol Behav 55:789-793

Badiani A, Morano MI, Akil H, Robinson TE (1995): Circulating adrenal hormones are not necessary for the development of sensitization to the psychomotor activating effects of amphetamine. Brain Res 673:13-24

Becker JB (1990): Direct effect of 17B-estradiol on striatum: Sex differences in dopamine release. Synapse 5:157-164

Becker JB, Cha JH (1989): Estrous cycle-dependent variation in amphetamine-induced behaviors and striatal dopamine release assessed with microdialysis. Behavior Brain Res 35:117-125

Becker JB, Robinson TE, Lorenz KA (1982): Sex differences and estrous cycle variations in amphetamine-elicited rotational behavior. Eur J Pharmacol 80:65-72

Borowsky B, Kuhn CM (1991): Monoamine mediation of cocaine-induced hypothalamo-pituitary-adrenal activation. J Pharmacol Exp Ther 256:204-210

Borowsky B, Kuhn CM (1993): GBR 12909 stimulates hypothalamo-pituitary-adrenal activity by inhibition of uptake at hypothalamic dopamine neurons. Brain Res 613:251258

Bowman BP, Vaughan SR, Rehder NM, Thomas BF, Kuhn CM (1996): Gender differences in the metabolism of cocaine in the rat. Committee on Problems of Drug Dependence (CPDD) Annual Meeting 
Buckingham JC (1982): Effects of adrenocortical and gonadal steroids on the secretion in vitro of corticotrophin and its hypothalamic releasing factor. J Endocrinol 93:123133

Burgess BH, Handa RJ (1992): Chronic estrogen-induced alterations in adrenocorticotropin and corticosterone secretion, and glucocorticoid receptor mediated functions in female rats. Endocrinology 131:1261-1269

Cador M, Cole BJ, Koob GF, Stinus L, Le Moal M (1993): Central administration of corticotropin releasing factor induces long-term sensitization to d-amphetamine. Brain Res 606:181-186

Camp DM, Robinson TE (1988a): Susceptibility to sensitization I. Sex differences in the enduring effects of chronic d-amphetamine treatment on locomotion, stereotyped behavior and brain monoamines. Behav Brain Res 30:55-68

Camp DM, Robinson TE (1988b): Susceptibility to sensitization II. the influence of gonadal hormones on enduring changes in brain monomaines and behavior produced by the repeated administration of d-amphetamine or restraint stress. Behav Brain Res 30:69-88

Chisari A, Carino M, Gaillad RD, Spinedi E (1995): Sex and strain variability in the rat hypothalamo-pituitary-adrenal (HPA) axis function. J Endocrinol Invest 18:25-33

Critchlow V, Liebelt RA, Bar-Sela M, Mountcastle W, Lipscomb HS (1963): Sex difference in resting pituitaryadrenal function in the rat. Amer J Physiol 205:807-815

Cole BJ, Cador M, Stinus L, Rivier C, Rivier J, Vale W, Le Moal M, Koob GF (1990a): Critical role of the hypothalamic-pituitary adrenal axis in amphetamine-induced sensitization of behavior. Life Sci 47:1715-1720

Cole BJ, Cador M, Stinus L, Rivier J, Vale W, Koob GF, Le Moal M (1990b): Central administration of a CRF antagonist blocks the development of stress-induced behavioral sensitization. Brain Res 512:343-346

Coyne MD, Kitay II (1969): Effect of ovariectomy on pituitary secretion of ACTH. Endocrinology 85:1097-1102

Coyne MD, Kitay JI (1971): Effect of orchiectomy on pituitary secretion of ACTH. Endocrinology 859:1024-1028

Derouche V, Piazza PV, Casolini P, Maccari S, Le Moal M, Simon H (1992): Stress-induced sensitization to amphetamine and morphine psychomotor effects depend on stress-induced corticosterone secretion. Brain Res 598: 343-348

Derouche V, Piazza P, Carolini P, Le Moal M, Simon H (1993): Sensitization to the psychomotor effects of amphetamine and morphine induced by food restriction depends on corticosterone secretion. Brain Res 611:352-356

Ehlers CL, Kaneko WM, Owens MJ, Nemeroff CB (1993): Effects of gender and social isolation on electroencephalogram and neuroendocrine parameters in rats. Biol Psych 33:358-366

Fuller RW (1990): Serotonin receptors and neuroendocrine responses. Neuropsychopharmacology 3:495-502

Haas DA, George SR (1988): Gonadal regulation of corticotropin-releasing factor immunoreactivity in hypothalamus. Brain Res Bull 20:361-367

Hary L, Dupouy JP, Chatelain A (1981): Pituitary response to bilateral adrenalectomy, metyrapone treatment and ether stress in the newborn rat. Biol Neonate 3:8-36

Hary L, Dupouy JP, Gregoire I (1986): Effects of castration and testosterone on the pituitary and adrenal responses of the newborn rat to ether inhalation. Neuroendocrinology 42:137-142

Hruska RE (1986): Elevation of striatal dopamine receptors by estrogen: Dose and time studies. J Neurochem 47:1908-1915

Kalivas PW, Duffy P, and Latimer LG (1987): Neurochemical and behavioral effects of corticotropin releasing factor in the ventral tegmental area of the rat. J Pharmacol Exp Ther 242:757-763

Kitay JI (1963) Pituitary-adrenal function in the rat after gonadectomy and gonadal hormone replacement. Endocrinology 73:253-260

Kuhn CM, Little PJ (1995): Neuroendocrine effects of cocaine. In Hammer RP (ed), The Neurobiology of Cocaine. Boca Raton, FL. CRC Press, pp 49-64

Lavicky J, Dunn A (1993): Corticotropin-releasing factor stimulates catecholamine release in hypothalamus and prefrontal cortex in freely moving rats as assessed by microdialysis. J Neurochem 60:602-612

Le Moal M, Simon H (1991): Mesocorticolimbic dopaminergic network: Functional regulatory roles. Physiol Rev 71:155-234

Le Mevel JC, Abitbol S, Beraud G, Maniey J (1978): Dynamic changes in plasma adrenocorticotrophin after neurotropic stress in male and female rats. J Endocrinol 76:359360

Le Mevel JC, Abitbol S, Beraud G, Maniey J (1979): Temporal changes in plasma adrenocorticotropin concentrations after repeated neurotropic stress in male and female rats. Endocrinology 105:812-817

Lesniewska B, Miskowiak B, Nowak M, Malendowicz LK (1990): Sex differences in adrenocortical structure and function. XXVII. The effect of ether stress on ACTH and corticosterone in intact, gonadectomized and testosterone- or estradiol-replaced rats. Res Exp Med 190:65-103

Levy AD, Li Q, Kerr JE, Rittenhouse PA, Milonas G, Cabrera TM, Battaglia G, Van de Kar LD (1991): Cocaineinduced elevation of plasma adrenocorticotropin hormone and corticosterone is mediated by serotonergic neurons. J Pharmacol Exp Ther 259:495-500

Levy AD, Baumann MH, Van de Kar LD (1994): Monoaminergic regulation of neuroendocrine function and its modification by cocaine. Frontiers Neuroendocrinol 15: $85-156$

Lukas S (1996): Gender-related differences in acute cocaine effects. Committee on Problems of Drug Dependence (CPDD) Annual Meeting

Marinelli M, Piazza P, Derouche V, Maccari S, Le Moal M, Simon H (1994): Corticosterone circadian secretion differentially facilitates dopamine-mediated psychomotor effect of cocaine and morphine. J Neurosci 14:2724-2731

Miskowiak B, Lesniewska B, Nowak M, Malendowicz (1988): Studies on hypothalamo-pituitary corticoliberin system V. The effects of gonadectomy and sex hormones on plasma ACTH on the reactivity of the anterior pituitary gland to CRF. Exp Clin Endocrinol 92:1-6 
Morissette M, Di Paolo T (1993): Effect of chronic estradiol and progesterone treatments of ovariectomized rats on brain dopamine uptake sites. J Neurochem 60:1876-1883

Meyer EM, Lytle LD (1978): Sex-related differences in the physiological disposition of amphetamine and its metabolites in the rat. Proc West Pharmacol Soc 21:313-316

National Institute of Drug Abuse (1990) National Household Survey on Drug Abuse, Main Findings. Publication No 91-1788. Washington, DC, U.S. Department of Health and Human Services, Alcohol, Drug Abuse, and Mental Health Administration

Patchev VK, Hayashi S, Orikasa C, and Almedia OFX (1995): Implications of estrogen-dependent brain organization for gender differences in hypothalamo-pituitary-adrenal regulation. FASEB J 9:419-423

Piazza PV, Maccari S, Deminiere JM, Le Moal M, Mormede P, Simon H (1991): Corticosterone levels determine individual vulnerability to amphetamine self-administration. Proc Natl Acad Sci 88:2088-2092

Piazza PV, Marinelli M, Jodogne C, Derouche V, Rouge-Pont F, Maccari S, Le Moal M, Simon H (1994): Inhibition of corticosterone synthesis by Metyrapone decreases cocaineinduced locomotion and relapse of cocaine self-administration. Brain Res 658:259-264

Plotsky PM, Cunningham ET, Widmaier EP (1989): Catecholaminergic modulation of corticotropin-releasing factor and adrenocorticotropin secretion. Endocrinol Rev 10:437-458

Redei E, Li L, Halasz I, McGivern RF, and Aird F (1996): Fast glucocorticoid feedback inhibition of ACTH secretion in the ovariectomized rat: Effect of chronic estrogen and progesterone. Neuroendocrinology 60:113-123

Rivier C (1993) Female rats release more corticosterone than males in response to alcohol: Influence of circulating sex steroids and possible consequences for blood alcohol levels. Alcohol Clin Exp Res 17:854-859

Rivier C (1996): Stimulatory effect of interleukin-1B on the hypothalamic-pituitary-adrenal axis of the rate: Influence of age, gender and circulating sex steroids. J Endocrinol 140:365-372

Rivier C, Vale W (1981): Cocaine stimulates adrenocorticotropin (ACTH) secretion through a corticotropin-releasing factor (CRF)-mediated mechanism. Brain Res 422: $403-406$
Rouge-Pont F, Marinelli M, Le Moal M, Simon H, Piazza PV (1995): Stress-Induced Sensitization and Glucocorticoids II. Sensitization of the Increase in Extracellular Dopamine Induced by Cocaine Depends on Stress-Induced Corticosterone Secretion. J. Neuroscience 15:7189-7195

Sarnyai Z, Biro E, Telegdy G (1992): Cocaine-induced elevation of plasma corticosterone is mediated by different neurotransmitter systems in rats. Pharmacol Biochem Behav 45:209-214

Savageau MM, Beatty WM (1981): Gonadectomy and sex differences in the behavioral responses to amphetamine and apomorphine of rats. Pharmacol Biochem Behav $14: 17-21$

Schoenfeld NM, Leathem JH, Rabii J (1980): Maturation of adrenal stress responsiveness in the rat. Neuroendocrinology 31:101-105

Shanks N, McCormick CM, Meaney MJ (1994): Sex differences in hypothalamic-pituitary-adrenal responding to endotoxin challenge in the neonate: Reversal by gonadectomy. Develop Brain Res 79:260-266

Spinedi E, Suescun MO, Hadid R, Daneva T, Gaillard RC (1992): Effects of gonadectomy and sex hormone therapy on the endotoxin stimulated hypothalamo-pituitaryadrenal axis: Evidence for a neuroendocrine-immunological sexual dimorphism. Endocrinology 131:24302436

Tang F, Phillips JG (1997): Pituitary-adrenal response to ether stress in the neonatal rat. J Endocrinol 75:183-184

Van Haaren F, Meyer ME (1991): Sex differences in locomotor activity after acute and chronic cocaine administration. Pharmacol Biochem Behav 39:923-927

Viau V, and Meaney MJ (1991): Variations in the hypothalamic-pituitary-adrenal response to stress during the estrous cycle in the rat. endocrinology 129:2503-2511

Walker CD, Scribner KA, Cascio CS, Dallman MF (1991): The pituitary-adrenocortical system of neonatal rats is responsive to stress throughout development in a timedependent and stressor-specific fashion. Endocrinology 128:1385-1395

Watts AG, Swanson LW (1989): Diurnal variations in the content of preprocorticotropin-releasing hormone messenger ribonucleic acids in the hypothalamic paraventricular nucleus of rats of both sexes as measured by in situ hybridization. Endocrinology 125:1734-1738 